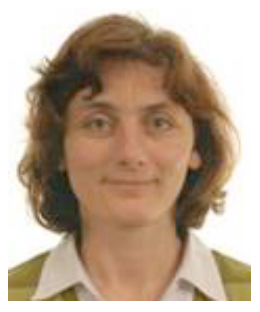

\title{
CO-PRODUCTION OF KNOWLEDGE IN SOILS GOVERNANCE
}

\author{
Katrin Prager \\ Senior Social Scientist \\ The James Hutton Institute \\ United Kingdom
}

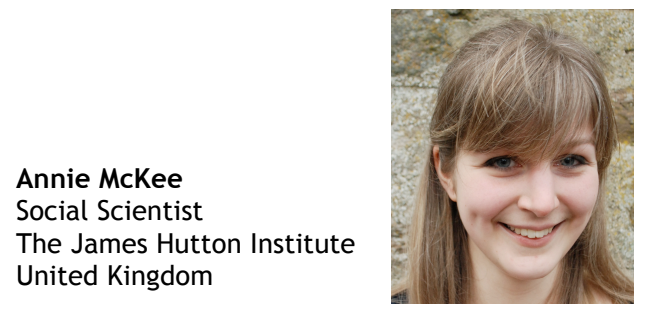

The co-production of knowledge between different actor groups has the potential to generate 'more socially robust knowledge' and better decisions, therefore improving governance processes. This paper explores knowledge co-production between different types of actors involved in soils governance in Scotland: policy makers, agency staff, scientists, local authorities, land managers and other stakeholders. In a setting characterised by network governance, we investigate knowledge co-production in three arenas that aimed to implement the Scottish Soil Framework and progress several activities such as a Soil Monitoring Action Plan and the Scotland's Soils website. Adopting an action research, case study approach, we collected data through document analysis, observation, personal communication with policy actors involved, and semi-structured interviews with soil data users (local authorities, farmers, estate managers). The findings show different levels of interaction in the different arenas, ranging from major interaction and two-way communication to no interaction. The interaction levels indicate the extent to which knowledge exchange has taken place. Analysis highlights the divergence in problem framing between the actor groups, their diverse soil data needs and, therefore, a variation in perceptions of solutions. The combination of co-production in the different arenas enhanced policy actors' knowledge and allowed them to reconsider policy implementation efforts. However, the delineation of knowledge types remains challenging since the same actor can hold different types of knowledge. We conclude that the concept of knowledge co-production is useful as a frame for developing polycentric, interactive and multiparty processes in soils governance, as well as to identify where interaction requires facilitation and/or improvement, but the concept does not provide a consistent theory.

\section{Introduction}

Environmental governance relies on decision-making in various arenas and is determined by a variety of actors who each hold a stake in the process. ${ }^{1}$ Decision-making is influenced by the knowledge that actors bring to the process. Their knowledge differs in terms of both content and orientation, ${ }^{2}$ and it emerges within different institutional and social contexts. ${ }^{3}$ Knowledge in complex decision-making processes is incomplete and often asymmetrically distributed between actors. ${ }^{4}$

The literature typically distinguishes between three types of knowledge, held by different groups of actors: ${ }^{5}$

- Scientific (or expert) knowledge

- Bureaucratic (administrative or policy-makers) knowledge

\footnotetext{
1 J Newig and O Fritsch, ‘Environmental Governance: Participatory, Multi-Level - and Effective?’ (2009) 19 Environmental Policy and Governance 197, DOI: 10.1002/eet.509.

2 M Brugnach and H Ingram, 'Ambiguity: The Challenge of Knowing and Deciding Together (2012) 15 Environmental Science and Policy 60, DOI: 10.1016/j.envsci.2011.10.005; J Eshuis and M Stuiver, 'Learning in Context Through Conflict and Alignment: Farmers and Scientists in Search of Sustainable Agriculture' 200522 Agriculture and Human Values 137, DOI: 10.1007/s10460-004-8274-0.

3 M Hajer and H Wagenaar, 'Deliberative Policy Analysis. Understanding Governance in the Network Society' in R Goodin (ed), Theories of Institutional Design. (Cambridge University Press, 2003) 307.

4 R Birner and $\mathrm{H}$ Wittmer, 'On the "Efficient Boundaries of the State": The Contribution of Transaction-Costs Economics to the Analysis of Decentralization and Devolution in Natural Resource Management' (2004) 22 Environment and Planning C: Government and Policy 667, DOI: 10.1068/c03101s.

5 K Bäckstrand, 'Civic Science for Sustainability: Reframing the Role of Experts, Policy-Makers and Citizens in Environmental Governance’ (2004) 3 Global Environmental Politics 24, DOI: 10.1162/152638003322757916; J Edelenbos, A van Buuren and $\mathrm{N}$ van Schie, 'Co-Producing Knowledge: Joint Knowledge Production Between Experts, Bureaucrats and Stakeholders in Dutch Water Management Projects' (2011) 14 Environmental Science and Policy 675, D0I: 10.1016/j.envsci.2011.04.004; J D Rinaudo and P Garin, 'The Benefits of Combining Lay and Expert Input for Water-Management Planning at the Watershed Level’ (2005) 7 Water Policy 279.
} 
- $\quad$ Stakeholder (citizens, lay, practical, or non-scientific) knowledge

These are also commonly described as the research, policy and practice domains. ${ }^{6}$ We speak of knowledge coproduction when actors from these groups interact with the aim of 'exchanging, combining and harmonizing elements like facts, interpretations, assumptions and causal relations from their different knowledge domains'. ${ }^{7}$ Ultimately, knowledge co-production is expected to lead to a common knowledge platform, which is authoritative for actors from the different domains. ${ }^{8}$ Brugnach and Ingram specify that the process of knowledge co-production refers to how knowledge is processed and how new knowledge is created that represents a new socially constructed reality. ${ }^{9}$

The co-production of knowledge between these different groups of actors has the potential to lead to 'more socially robust knowledge', ${ }^{10}$ better decisions and, thus, to improved governance. More socially robust knowledge is better suited to address 'wicked problems'. Wicked problems ${ }^{11}$ refer to situations where there are different definitions and interpretations of a problem, the problem affects a range of stakeholders, and there are no definitive solutions. Especially in environmental governance, including soil governance, those who make and implement policy are faced with wicked problems. According to Coburn, ${ }^{12}$ local knowledge can enhance professional knowledge through: a) offering insights about places and populations that take history and biography into account, aspects that professional science routinely ignores; b) rectifying the tendency toward reductionism in science and extending the knowledge-base used for decision-making; c) improving scientific assessments by re-valuing information that was ruled out by professionals; and d) making normative contributions to environmental science and policy such as enhanced procedural democracy. The literature emphasises that different types of actors need to engage in dialogue and cooperate in order to create sustainable knowledge; for example, farmers and scientists, ${ }^{13}$ lay/local people and professionals, ${ }^{14}$ different scientific disciplines and relevant societal groups, ${ }^{15}$ or science and public policy. ${ }^{16}$

Although knowledge co-production is associated with benefits, it also creates tensions for various reasons. For example, due to different perspectives and interests of the actors involved, different languages, norms and values, or due to lacking communication and trust. ${ }^{17}$ Maiello et al comment that 'the types and ways to produce knowledge are important issues for environmental governance'. ${ }^{18}$ This statement arises from the concept that knowledge is socially constructed, ${ }^{19}$ which means that public decisions need to be based on different types of knowledge and not exclusively on scientific or expert knowledge.

While the role of knowledge in environmental governance has been previously investigated - particularly with regard to water and climate change ${ }^{20}$ - soils governance has not yet been the focus of such analyses. In

6 R Wehrens, 'Beyond Two Communities - From Research Utilization and Knowledge Translation to Co-Production?’ (2014) Public Health, 128(6), 545, DOI: 10.1016/j.puhe.2014.02.004.

Edelenbos, van Buuren, van Schie, above n 5, 676.

8 Ibid.

9 Brugnach and Ingram, above $\mathrm{n} 2$.

${ }^{10} \mathrm{D}$ Hegger et al, 'Conceptualising Joint Knowledge Production in Regional Climate Change Adaptation Projects: Success Conditions and Levers for Action' (2012) 18 Environmental Science and Policy 52, 55, DOI: 10.1016/j.envsci.2012.01.002.

${ }^{11}$ E P Weber and A M Khademian, 'Wicked Problems, Knowledge Challenges, and Collaborative Capacity Builders in Network Settings' (2008) 68 Public Administration Review 334, DOI: 10.1111/j.1540-6210.2007.00866.x.

12 J Corburn, 'Community Knowledge in Environmental Health Science: Co-Producing Policy Expertise' (2007) 10 Environmental Science and Policy 10 150, DOI: 10.1016/j.envsci.2006.09.004.

${ }^{13}$ Eshuis and Stuiver, above $\mathrm{n} 2$.

${ }^{14}$ Coburn, above $\mathrm{n} 12$.

${ }^{15}$ W Mauser et al, 'Transdisciplinary Global Change Research: The Co-Creation of Knowledge for Sustainability' (2013) 5 Current Opinion in Environmental Sustainability 420, DOI: 10.1016/j.cosust.2013.07.001.

${ }^{16}$ Hegger et al, above n 10; T A Muñoz-Erickson, 'Co-Production of Knowledge-Action Systems in Urban Sustainable Governance: The KASA Approach’ (2014) 37 Environmental Science and Policy 182, DOI: 10.1016/j.envsci.2013.09.014.

${ }^{17}$ G M Hickey et al, 'Managing the Environmental Science-Policy Nexus in Government: Perspectives from Public Servants in Canada and Australia' (2013) 40 Science and Public Policy 529, DOI: 10.1093/scipol/sct004; J Ingram, P Fry and A Mathieu, 'Revealing Different Understandings of Soil Held by Scientists and Farmers in the Context of Soil Protection and Management' (2010) 27 Land Use Policy 51, DOI: 10.1016/j.landusepol.2008.07.005; P Spruijt et al, 'Roles of Scientists as Policy Advisers on Complex Issues: A Literature Review (2014) 40 Environmental Science and Policy 16, DOI: 10.1016/j.envsci.2014.03.002.

${ }^{18}$ A Maiello et al, 'Public Managers as Catalysts of Knowledge Co-Production? Investigating Knowledge Dynamics in Local Environmental Policy’ (2013) 27 Environmental Science and Policy 141, DOI: 10.1016/j.envsci.2012.12.007.

${ }^{19}$ B Latour, Pandora's Hope: Essays on the Reality of Science Studies (Harvard University Press, Cambridge, 1999).

${ }^{20}$ Hegger et al, above n 10; C Mauelshagen et al, 'Effective Risk Governance for Environmental Policy Making: A Knowledge Management Perspective' (2014) 41 Environmental Science and Policy 23, DOI: 10.1016/j.envsci.2014.04.014; M J NurseyBray, 'Science into Policy? Discourse, Coastal Management and Knowledge' (2014) 38 Environmental Science and Policy 107, DOI: 10.1016/j.envsci.2013.10.010; C Pahl-Wostl, ‘From Applying Panaceas to Mastering Complexity: Toward Adaptive Water Governance in River Basins (2012) 23 Environmental Science and Policy 24, DOI: 10.1016/j.envsci.2012.07.014. 
addition, the concept of knowledge co-production has not yet been linked explicitly to soil governance. This paper looks at the particular role of knowledge co-production in the process of soils governance, using an example of how knowledge is generated, interpreted and used in the context of progressing soil policy in Scotland. The main aim is to identify how the combination of different types of knowledge can influence soil governance. A focus of the study was on knowledge generation and interpretation based on the coconstruction of the problem and its possible solution between researchers and policy actors, and we expect that the framing that actors bring to the problem influences the co-construction process. ${ }^{21}$ We have deliberately set out to co-construct research questions with policy makers for the processes around soil policy (action research), and to reflect on the impact of the research activities.

\section{Conceptual approach and methods}

\section{Soils governance and knowledge co-production}

Governance is understood as 'the totality of interactions of governments, other public bodies, the private sector and civil society, aiming to solve societal problems or creating societal opportunities'. ${ }^{22}$ Within this very broad definition, Lowndes and Skelcher point to the interpretive and 'sense-making' side of the governance process. They stress that different modes of governance are 'the outcome of social processes but also provide the medium through which actors interpret and act to shape their reality'. ${ }^{23}$ An investigation of governance places the focus on the relations between governmental actors and societal actors when addressing public issues. It may be assumed that relationships between actors involved in soil governance are formed by interactions and communication; therefore, interaction is necessary for the co-production of knowledge. ${ }^{24}$ In particular, the transfer of tacit knowledge (the tacit dimensions beyond explicit knowledge or information) requires intimate human interaction. ${ }^{25}$ Interpretation of facts and information is a core element of the governance process.

While co-production is seen to be beneficial to the governance process because it brings in different types of information, it may, for various reasons, also create tensions. In some instances, tensions are caused by differences in perspective. ${ }^{26}$ For example, many policymakers seek certainties and solutions, whereas scientists typically offer probabilities, uncertainty and multiple scenarios. ${ }^{27}$ In addition, the different types of knowledge are essentially part of different practices associated with different languages, different norms and values, different systems of warrants and their own rules of the game, procedures and criteria. ${ }^{28}$

Regarding the science-policy interface, a lack of communication, trust and collaboration can seriously hamper the integration of scientific knowledge in environmental policy processes. ${ }^{29} \mathrm{~A}$ lack of trust and communication will have negative consequences for a knowledge co-production process. Regarding the co-production of knowledge with stakeholders, Edelenbos et al showed that, 'in general, both experts and bureaucrats are not willing to acknowledge that stakeholder knowledge has the potential to improve the identification of problems and the search for feasible solutions'. ${ }^{30}$ Petts and Brooks described this as the continuing expert-deficit model of lay knowledge (ie the public is seen to misunderstand environmental problems and have a knowledge deficit) and acknowledged the necessity for a cultural shift in expert understanding of the value of lay knowledge. ${ }^{31}$ In turn, many natural resource managers hold the stereotypical view that scientists seldom address 'real' problems, and do not work at appropriate or useful spatial and temporal scales. ${ }^{32}$

\footnotetext{
${ }^{21}$ Brugnach and Ingram, above n 2; Hegger et al, above n 10.

${ }^{22}$ L Meuleman, 'The Cultural Dimension of Metagovernance: Why Governance Doctrines May Fail' (2010) 10 Public Organizationl Review 49, DOI: 10.1007/s11115-009-0088-5.

${ }^{23} \mathrm{~V}$ Lowndes and C Skelcher, 'The Dynamics of Multi-Organisational Partnerships: An Analysis of Changing Modes of Governance’ (1998) 76 Public Administration, 318, DOI: 10.1111/1467-9299.00103.

${ }^{24}$ Brugnach and Ingram, above n 2; J Habermas, The Theory of Communicative Action: Reason and the Rationalization of Society (Heineman, London, vol 1, 1981); P Watzlawic, J B Bavelas and D D Jackson, Pragmatics of Human Communication: A Study of Interactional Patterns, Pathologies and Paradoxes (Norton, 2011).

${ }^{25}$ D J Roux et al, 'Bridging the Science - Management Divide: Moving from Unidirectional Knowledge Transfer to Knowledge Interfacing and Sharing' (2006) 11 Ecology and Society [online] URL: http://www.ecologyandsociety.org/vol11/iss1/art4/.

${ }^{26}$ Hegger et al, above n 10.

27 Spruijt et al, above n 17.

${ }^{28}$ Edelenbos et al, above n 5; Ingram et al, above n 17.

${ }^{29}$ Hickey et al, above $\mathrm{n} 17$.

${ }^{30}$ Edelenbos et al, above n 5, 682.

$31 \mathrm{~J}$ Petts and C Brooks, 'Expert Conceptualization of the Role of Lay Knowledge in Environmental Decision Making: Challenges for Deliberative Democracy’ (2006) 38 Environment And Planning 1045, DOI:10.1068/a37373.

${ }^{32}$ Roux et al (2006), above n 25.
} 
Unlike water or air pollution policies, which have dedicated policy frameworks, aspects of soil protection feature in many different policies but there is no coherent policy framework around soils in many countries. ${ }^{33}$ This means soils governance is characterised by the involvement of a diverse range of actors from different sectors (agricultural, environmental, forestry, conservation, water) and different organisations (agencies, NGOs, academic organisations, lobby groups) across different levels (EU to local).

It is important to consider the national cultures and politico-administrative traditions in a given context, as these co-determine the appropriate governance mixture. ${ }^{34}$ Unlike other European countries, such as Germany, the Netherlands, the Czech Republic and Bulgaria, the UK does not have soil protection legislation. ${ }^{35}$ Legislative power on natural resources, agriculture and the environment are devolved. Therefore, each of the UK countries can regulate and legislate as appropriate for their situation. In England, the Department for Environment, Food and Rural Affairs (DEFRA) prepared a Soil Action Plan for England, which was launched in 2004. According to Meuleman, a soil protection Act was not politically feasible and a soil protection policy was politically not urgent. ${ }^{36}$ The Soil Action Plan for England 'was produced against the background of a marketliberal national culture with an anti-legislation attitude'. ${ }^{37}$ This national culture can be assumed to also apply in Scotland, as one of the devolved administrations of the UK.

The Scottish Government developed a Soils Strategy, which became the Scottish Soils Framework, following consultation in 2008. It was ultimately published in $2009 .{ }^{38} \mathrm{It}$ aims to 'enable soils to adapt to pressures under a changing climate' and 'raise awareness about the services provided, and pressures faced, by soils'. ${ }^{39}$ The Framework identifies a range of activities that will contribute to achieving these outcomes. The Scottish Soil Framework's actions are listed in its strategic environmental assessment post-adoption Statement. ${ }^{40}$ As one of the actions, the State of Scotland's Soils Report was published in March 2011. ${ }^{41}$

In addition to the Framework, which focuses explicitly on soil, there are various policies which indirectly affect soil (Table 1). Some originate at the European level and are subsequently transposed into national legislation. Rather than targeting soils directly, many policies have soil conservation as a by-product only.

Meuleman distinguishes three governance styles: market, network and hierarchy. ${ }^{42}$ These styles are ideal types and, in real situations, there are mixtures of styles. Nevertheless, each style is internally consistent and has distinct internal logic, as explained:

The central value of hierarchical governance is authority; therefore the output must be authoritative and legitimate. Empathy and trust are central in network governance, and therefore results are expected to be based on consensus. Market governance is based on competition and price, which makes it logical that the best results are the most competitive and cheapest products. This internal logic seems so attractive that many public managers and politicians adopted one of the styles as their belief system or doctrine. To them it presents a truth that has to be accepted without proof. ${ }^{43}$

According to Meuleman, ${ }^{44}$ market and network governance styles are dominant in the UK and people are used to these governance styles. Our investigation takes characteristics of the governance process into account to reaffirm the Scottish situation in the range of governance styles.

${ }^{33}$ K Prager, J Prazan and I Penov, 'Soil Conservation in Transition Countries: The Role of Institutions' (2012) 22 Environmental Policy and Governance 55, DOI: 10.1002/eet.592; K Prager et al, 'Soil Degradation, Farming Practices, Institutions and Policy Responses: An Analytical Framework. (2011) 22, Land Degradation and Development 46, DOI: $10.1002 /$ ldr. 979

${ }^{34}$ Meuleman, above n 22.

${ }^{35}$ Prager et al, (2011), above n 33.

${ }^{36}$ Meuleman, above n 22.

37 Ibid 61.

${ }^{38}$ Scottish Government, The Scottish Soil Framework, Edinburgh (2009) <http://www.scotland.gov.uk/Publications/2009/ 05/20145602/0>.

${ }^{39}$ Scottish Government, Soil Policy Framework (2013b) <http://www.scotland.gov.uk/Topics/Environment/soil/soilpolicy> .

${ }^{40}$ Halcrow Group Ltd, Scottish Soil Framework's Strategic Environmental Assessment Post-Adoption Statement (2010) Scottish Government <http://www.scotland.gov.uk/Topics/Environment/soil/soilpolicy/soilSEA>.

${ }^{41}$ K E Dobbie, P M C Bruneau and W Towers, The State of Scotland's Soil (2011) Natural Scotland. www.sepa.org.uk/land/land_publications.aspx.

${ }^{42}$ Meuleman, above $\mathrm{n} 22$.

43 Ibid, 51.

44 Ibid. 
Table 1: Overview of soil policy in Scotland ${ }^{45}$

\begin{tabular}{|c|c|}
\hline Scottish policy/guidance & Scottish legislation \\
\hline $\begin{array}{l}\text { - } 2020 \text { Route map - Renewables } \\
\text { - } \text { Land Use Strategy (2011) and action } \\
\text { - Scottish Government's discussion paper } \\
\text { on the management of carbon rich soils } \\
\text { (2010) } \\
\text { - Scottish Planning Policy (2010) } \\
\text { - Scotland's Zero Waste Plan (2010) } \\
\text { - National Planning Framework } 3 \text { (2014) } \\
\text { - Planning Advice Note } 33 \text { (Development } \\
\text { - } \text { Scontaminated land) } \\
\text { - Scottish Soil Framework (2009) } \\
\text { - Scottish Rural Development Programme } \\
\text { Cross Compliance - Good Agricultural } \\
\text { and Environmental Conditions (GAEC) } \\
\text { (2007) } \\
\text { - Scottish Forestry Strategy (and } \\
\text { implementation Plan) (2006) } \\
\text { - Scotland's Biodiversity Strategy (2012) } \\
\text { - } \text { River Basin Management Plans } \\
\text { - Scottish Historic Environment Policy }\end{array}$ & 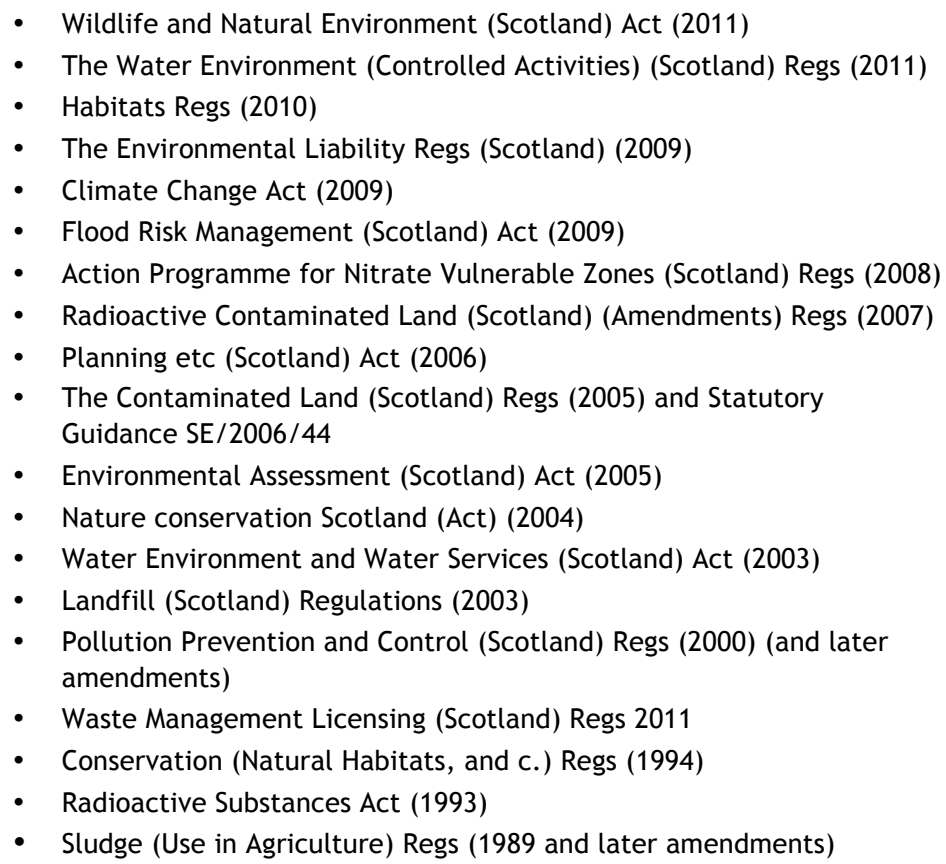 \\
\hline
\end{tabular}

\section{Methods}

We applied the case study method ${ }^{46}$ to study knowledge co-production and framing of the problem among the particular actors involved in an action arena of soil governance. We selected the process of implementing the Scottish Soil Framework (2009), which entailed a number of activities, such as developing a Soil Monitoring Action Plan and the Scotland's Soils website (http://www.soils-scotland.gov.uk/). This selection was based on the opportunity for interaction that came about as a result of delivering research within the Scottish Government funded research programme 2011-2016.

In order to analyse the co-production of knowledge and its influence on governance, we borrow the concept of 'action arenas' from institutional analysis. According to Ostrom, an action arena is where participants interact in an action situation. ${ }^{47}$ Their interactions are affected by exogenous variables and produce outcomes that, in turn, affect the participants and the action situation. Action arenas are delineated as appropriate to the analysis; they may refer to interactions in a local context and in national councils, as well as in government, firms and markets. For an example of applying action arenas to soil governance see Prager et al. ${ }^{48}$

In a first step, we analysed the types of actors and the knowledge they brought to the process of coproduction in the relevant action arena. The divisions used in the literature (scientific/expert knowledge, bureaucratic/policy-makers knowledge and stakeholder/practical knowledge) have limited applicability for our case. As acknowledged by Edelenbos et al, ${ }^{49}$ the categories neglect the (sometimes huge) diversity within the categories, and that the selection of experts and stakeholders is a political and biased process. We, therefore, adjust the categories to fit the specific context of the case study and endeavour to counter potential bias by being as transparent as possible about the selection process.

\footnotetext{
${ }^{45}$ Based on examples of policies, legislation and guidance which may require soil information as part of their development and implementation compiled in H Black, P Bruneau and K Dobbie, Soil Monitoring Action Plan (2012) Scottish Government <http://www.environment.scotland.gov.uk/media/59999/Soil_Monitoring_Action_Plan.PDF>.

${ }^{46} \mathrm{R} K \mathrm{Y}$ Yin, Case Study Research Design and Methods (Sage, $3^{\text {rd }} \mathrm{Ed}, 2003$ ).

${ }^{47}$ E Ostrom, Understanding Institutional Diversity (Princeton University Press, Princeton, NJ, 2005).

48 Prager et al, (2011), above n 33.

${ }^{49}$ Edelenbos et al, above n 5.
} 
Two distinct sets of knowledge are involved in our case: scientific and non-scientific knowledge (Figure 1; Table 2). Other authors have termed this academic and non-academic knowledge. ${ }^{50}$ Scientific knowledge is mainly produced by experts with formal training. This type of knowledge is institutionalised and based on systematic and methodical inquiry with quality checks through a community of peers. ${ }^{51}$ Differences between the natural and social sciences have been acknowledged in terms of their use of different premises, methodologies, norms and values. ${ }^{52}$ Our case involves natural and social scientists (Figure 1).

Non-scientific knowledge comprises subcategories of knowledge types, including stakeholder (citizens, lay, practical, or non-scientific) knowledge and bureaucratic (policy actor, ${ }^{53}$ administrative) knowledge.

Stakeholder knowledge is grounded in the experience of the individuals, and thus contextual and local. ${ }^{54}$ It is also described as implicit, based on common sense and derived from stakeholders' practices. ${ }^{55}$

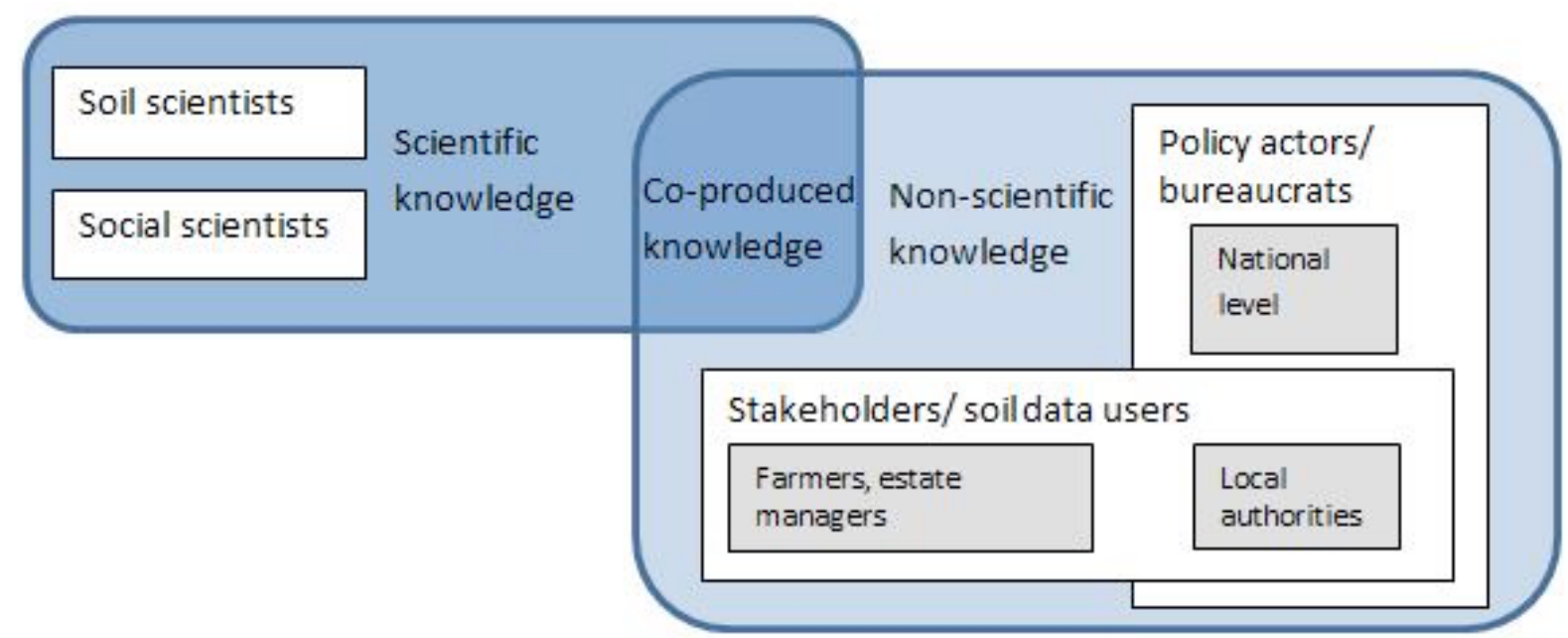

Figure 1: Representation of the knowledge types involved in soil governance in the Scottish case study

Bureaucratic knowledge refers to the knowledge of administrators, policy makers, and staff in governmental agencies. They possess knowledge of the formal procedures (laws, regulations, norms) which is 'grounded in the understanding of relational and political dimensions of the social context'. ${ }^{56}$ Bureaucratic knowledge draws on scientific beliefs (universal) but is also context specific (local). It stresses the political and strategic use of knowledge. ${ }^{57}$

In our case study, policy actors at the national level hold bureaucratic knowledge. Stakeholder knowledge is brought to the process through two different groups with practical knowledge (farmers and estate managers). Staff of local authorities (LAs) represent a hybrid: they hold both bureaucratic knowledge and stakeholder knowledge. LAs and practitioners have in common that they are both soil data users (Figure 1).

According to Hegger et al, 'co-production mechanisms are often indirect and hard to discern'. ${ }^{58}$ The opportunity for action research in this case allowed the collection of data on co-production mechanisms. The social researchers were involved in what can be described an action research process. ${ }^{59}$ This means that they were involved in the process as actors and conscious of the fact that they influenced it, whilst also stepping back and reflecting on the events and discourses. The active research period ran from February 2013 to March 2014.

\footnotetext{
${ }^{50}$ Mauser et al, above n 15; C Pohl et al, 'Researchers' Roles in Knowledge Co-Production: Experience from Sustainability Research in Kenya, Switzerland, Bolivia and Nepal' (2010) 37 Science and Public Policy 267, DOI:10.3152/030234210X496628.

${ }^{51}$ Petts and Brooks, above $\mathrm{n} 31$.

${ }^{52} \mathrm{H}$ Nowotny, P Scott and M Gibbons, Re-Thinking Science: Knowledge and the Public in an Age of Uncertainty (Polity Press, 2001).

${ }^{53}$ The term 'policy actor' is used in the remainder of the paper to encompass policy makers, administrators and agency staff in Scottish Government.

${ }^{54}$ Petts and Brooks, above n 31.

${ }^{55}$ Edelenbos, above $\mathrm{n} 5$; Maeillo et al, above $\mathrm{n} 18$.

${ }^{56}$ Maiello et al, above $\mathrm{n} 18$.

${ }^{57}$ Edelenbos, above $\mathrm{n} 5$.

${ }^{58}$ Hegger et al, above n 10, 53.

${ }^{59}$ S Kindon, R Pain and M Kesby, 'Participatory Action Research: Origins, Approaches and Methods', in S Kindon, R Pain and M Kesby (eds), Participatory Action Research Approaches and Methods (Routledge, Oxon, 2007) 9.
} 
In order to identify the interaction between various actors, we conducted interviews with representatives of the soil data users group (Table 2, arena 3). There are 32 LAs in Scotland. We interviewed ten staff from LAs across Scotland who had responded to the invitation to participate in an interview and who used soil data as part of their work. Other stakeholders represented land managers, including nine farmers and four estate managers (managers of large land holdings). Members of the farming community and estate managers previously known to the researchers were invited to participate in an interview. In this purposive sampling method, farmers were approached from a diverse range of farm types, sizes and locations (eg, upland, coastal) from across Aberdeenshire and Moray (North East Scotland), and estate managers from a range of estate ownership types, sizes and locations. It was beneficial to utilise existing contacts to land managers because it provides accessibility, built on established trust, though different views might have been missed. Nonetheless, the sampling enabled views to be gathered from a diverse set of land managers.

Table 2: Overview of activities and co-production processes investigated

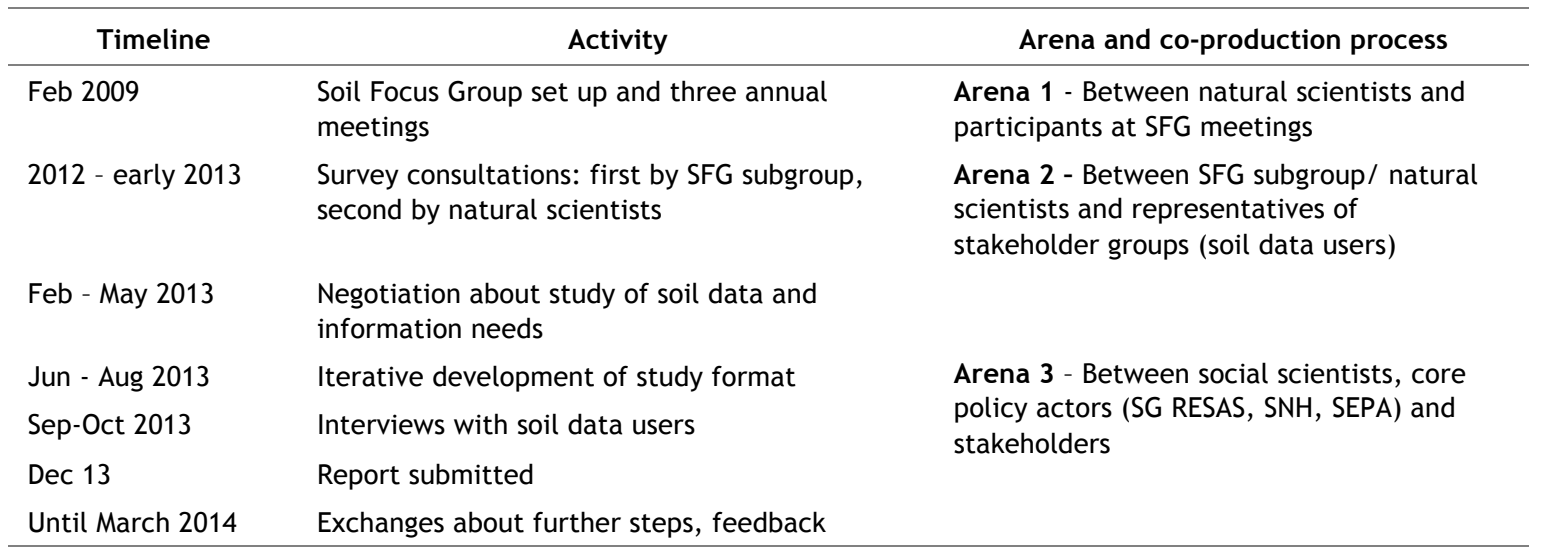

The question guide was similar for all three types of interviewees but adjusted to their respective contexts. Interviews typically lasted between 30 and 40 minutes, and were conducted over the telephone. Notes from the interviews were typed and thematically coded according to the interview guide: 1 ) What (soil) data/information needs do different users have and what barriers do they perceive to accessing and using soil data/information?; 2) How can approaches to provide soil information/interpretation be enhanced for different user groups?; and 3) What is the best format for different users to access soil information? This set of empirical data is referred to as 'the interview study'.

Information on interactions between natural scientists, policy actors and stakeholders (arenas 1 and 2) was drawn from minutes of meetings ${ }^{60}$ and from informal exchanges, including email, personal communication and comments on documents. Minutes, emails and document comments were analysed by coding statements to emerging themes. This secondary data set is referred to as the 'interaction analysis'.

The authors represent the social scientists. Researcher colleagues represent the natural scientists (mainly soil scientists). Both types of scientists work in the same research institute.

Bureaucrats/policy actors at the national level include the Scottish Government's Rural and Environment Science and Analytical Services Division (SG RESAS), the Scottish Government's Environmental Quality Division's Soil and Contaminated Land Team, and representatives of Scottish Non-Departmental Public Bodies (NDPBs); that is, Scottish Natural Heritage (SNH) and Scottish Environment Protection Agency (SEPA). The Soil Focus Group (SFG) was established in February 2009 as part of the Scottish Soil Framework (SSF) ${ }^{61}$ to bring together the key delivery partners and stakeholders, and to advise the Scottish Government on the Framework's implementation. Participant groups represented at Soil Focus Group meetings during 2011 included:

- $\quad$ Scottish Government (SG) Soil/Contaminated Land (Chair)

\footnotetext{
${ }^{60}$ Four minutes of SFG meetings is available: Scottish Government, Soil Policy Groups: Soil Focus Group (2008) <http://www.scotland.gov.uk/Topics/Environment/soil/policygroups>.

${ }^{61}$ The Scottish Government, The Scottish Soil Framework: Annex B: Soil Focus Group (February 2009) <http: //www.scotland.gov.uk/Publications/2009/05/20145602/11>.
} 
- $\quad$ SG RESAS; SG Agriculture and Rural Delivery (Rural Payments Inspection Directorate, RPID), SG Biodiversity Strategy, SG Natural Resources and Flooding, SG Water Environment Team

- $\quad$ Scottish Environment Protection Agency (SEPA)

- Scottish Natural Heritage (SNH)

- Scottish Land and Estates

- $\quad$ Royal Society for the Protection of Birds (RSPB) (representing Environment LINK)

- National Farmers Union Scotland

- Crofters Commission

- Forestry Commission Scotland

- Soil scientists from the James Hutton Institute

Finally, in order to analyse the co-production processes, we distinguish between levels of interaction as operationalised by Edelenbos et al and presented in Table 3.

Table 3: Levels of Interaction, as described by Edelenbos et al (2011)

\begin{tabular}{|c|c|}
\hline $\begin{array}{l}\text { Level of } \\
\text { interaction }\end{array}$ & Characteristics \\
\hline $\begin{array}{l}\text { Major interaction } \\
\text { and two way } \\
\text { communication }\end{array}$ & $\begin{array}{l}\text { - } \quad \text { joint activities to develop a common knowledge base } \\
\text { - } \\
\text { - } \\
\text { - } \\
\text { activen and communicative attitude } \\
\text { - } \quad \text { meceptive to other insights and sources of knowledge } \\
\text { decision } \\
\text { - } \\
\text { knowledge differences are displayed through a process of communication, } \\
\text { negotiation and mutual adjustment } \\
\text { explicit attention for bringing together knowledge from different domains by using } \\
\text { certain methods and procedures } \\
\text { realise an open dialogue and equal participation of actors }\end{array}$ \\
\hline $\begin{array}{l}\text { Medium interaction } \\
\text { and one way } \\
\text { communication }\end{array}$ & $\begin{array}{l}\text { - joint activities are developed strategically or symbolically with no real intention } \\
\text { to create a common knowledge base } \\
\text { - } \quad \text { actors meet, but do not actively express their own information and knowledge } \\
\text { - } \quad \text { do not really receptive to other sources of knowledge } \\
\text { and combined knowledge } \\
\text { - } \text { much difference between the knowledge assumptions and values, displayed in } \\
\text { one-way communication } \\
\text { - } \\
\text { interaction focussed on convincing the other of own assumptions and values } \\
\text { focus on consultation: actors can react but a reflexive dialogue is absent }\end{array}$ \\
\hline $\begin{array}{l}\text { Minor or absent } \\
\text { interaction }\end{array}$ & $\begin{array}{l}\text { - } \text { no joint knowledge co-production activities are developed } \\
\text { - } \quad \text { no explicit intention to create a common knowledge base } \\
\text { - } \text { disagreement and/or mutual misapprehension } \\
\text { - } \quad \text { knowledge is developed in a solitary manner, i.e. actors show no intentions to } \\
\text { include other values and perspectives } \\
\text { - } \quad \text { interaction takes the form a priori excluding certain values and perspectives } \\
\text { - } \quad \text { no common and supported knowledge base is created }\end{array}$ \\
\hline
\end{tabular}

During the interaction analysis we considered the totality of elements of interaction known to the researcher in each arena. Depending on which characteristics were met, we attributed the appropriate level of interaction in order to arrive at an evaluation of knowledge co-production.

\section{Findings}

Based on a preliminary interaction analysis, documents and exchanges with policy actors, we identified three distinct arenas where co-production processes may have taken place and where we were able to make observations or gather data on these processes: the first between natural scientists and participants during Soil Focus Group meetings; the second between natural scientists/policy actors and representatives of stakeholder groups (via two independent survey consultations), and the third between social scientists, core 
policy actors and stakeholders (via an interview study: Table 2). We will present findings for each of them in turn. Note that the processes in the first two action arenas were not set up as a research project; hence, less data was collected and no formal interviews were carried out. There is a richer account of the third action arena as this actually involved social scientists and data was collected in interviews.

\section{Co-production arena 1: Soil Focus Group}

The publication of the Scottish Soil Framework ${ }^{62}$ indicates policy actors' interests to put soil protection higher on the agenda. They tried to frame the objectives in ways that made them interesting for other agencies and societal actors, such as farmers, by emphasising the link to climate change and the services provided by soils. According to Meulemann, ${ }^{63}$ the attempt to speak to the autonomy and self-interest of these actors can be interpreted as characteristic of market governance. The Soil Team in the Scottish Government had worked together with other agencies and researchers in their development of the Scottish Soil Framework, and continued this approach in its implementation, for example through the Soils Focus Group (network governance).

Similar to initiatives taken in England, where DEFRA seeks to build on regulatory measures that have been successful for water and air quality policies, SEPA (the Scottish regulatory force comparable to the Environment Agency - an NDPB of DEFRA) had pursued a hierarchical, regulatory approach. The issue of dealing with contaminated land had also been subject to a regulatory approach, through the planning procedure (hierarchical governance). In recent years, SEPA has changed the approach in their interaction with practitioners. For example, in priority catchments (catchments prioritised of being at high risk of diffuse water pollution), SEPA worked in partnership with farmers and other stakeholders to help ensure that local knowledge is used to drive change. Officers will not immediately pursue breaches of the General Binding Rules. ${ }^{64}$ Instead, they advise farmers and encourage a change of practice. This can be interpreted as adopting further aspects of network governance.

The aims of the SFG included: 'raising awareness of the Scottish Soil Framework, providing a platform for liaison and pooling of resources and information amongst key delivery partners and stakeholders; developing the activities set out in the SSF; and providing progress reports on the actions' ${ }^{65}$ Liaison and pooling of resources is characteristic of a network governance style. The group was chaired by the Scottish Government Soil Policy Team and allowed for structured interaction between policy makers, representatives of research providers (including natural scientists, such as soil scientists) and stakeholder representatives.

As part of the exchange, scientists and policy makers shared information and knowledge, for example on soil sampling gaps, work undertaken for the National Soil Inventory, cross-cutting issues such as the leaching of phosphates from fields into rivers, effects of woodland expansion on locking up carbon, conflicting definitions for what constitutes peatlands, or other carbon-rich soils (documented in SFG minutes).

Due to the remit of the group to propose action to progress the implementation of the SSF (as a co-ordination forum and not supplanting specific responsibilities of member organisations), the group's leaders emphasised that members produce specific deliverables for their sector. This was not straightforward for all participants; in particular where the organisation they represented had a differing philosophy. For example, a preference for expressing objectives in terms of 'have regard to', rather than 'the organisation will'. This example resonates with the literature on different perspectives, norms and values that can cause tensions in coproduction processes. ${ }^{66}$ Knowledge co-production represents a shift from a hierarchical governance style to a network style, therefore leading to an opportunity and need for a re-negotiation of power; for example, with regard to enforceability.

It is also questionable to what extent there was the opportunity to co-produce knowledge within the SFG. With only up to three meetings per annum and changing participants, group dynamics may have hindered effective knowledge co-production, especially with non-policy actors. Newcomers would have had to be brought up to a similar level as established participants. With several months between meetings, some topics may have become outdated, participants may not have had the time to keep abreast of developments or to follow up on questions raised at a previous meeting. It is also not clear to what extent the group developed a shared

\footnotetext{
${ }^{62}$ Scottish Government (2009), above n 38.

${ }^{63}$ Meuleman, above n 22.

64 SEPA, Improving Water Environments: Diffuse pollution

<http://www.sepa.org.uk/water/water_regulation/regimes/pollution_control/diffuse_pollution.aspx>.

65 The Scottish Government (2008), above n 60.

${ }^{66}$ Edelenbos et al, above n 5; Hegger et al, above n 10.
} 
understanding of the problem and developed ways to address it. The drivers (ambitions and needs) of participants are likely to have remained distinct. On the other hand, where a subgroup of the SFG supported a specific task (such as the Soil Monitoring Group), close collaboration between these individuals ensued to transform that task into actions to promote the SSF.

When assessing the knowledge co-production process in the arena of the SFG, the finding was that the process meets some criteria of the major interaction level and some of the medium interaction level (see Table 3). Within the SFG, during the period of analysis, actors met on a regular and organised basis, however the interaction was limited to natural scientists and policy actors, with few stakeholder representatives (as per the membership of the group). An active exchange of information took place, although parts of this occurred through email and forwarding information, documents and links after meetings (one-way communication), which points to a medium level of interaction. In addition, the core of the activities of the SSF was delivered via bi-/trilateral actions among policy actors (outside the SFG meetings) as documented in the SSF Progress Report. $^{67}$

Joint activities may have been created strategically without the intention to create a common knowledge base as this was not the main aim of the SFG. A policy actor's impression was that a key driver in some joint activities was the need to develop sound and robust evidence for policy implementation across all partners' interests. We cannot comment further on the communicative attitude, how receptive to other insights and sources of knowledge the participants were, nor how open the dialogue was as this is not apparent from the minutes. Knowledge from different domains was brought together, although no particular methods were used and there is no evidence that explicit attention may have been paid to this aspect.

There was no interaction with the actual land manager on the ground, nor with LAs at this stage. LAs were invited via their representative body (Convention of Scottish Local Authorities (COSLA)) but never attended. In this regard, knowledge co-production was limited to two domains of knowledge: soil scientists and policy actors - although some stakeholder representatives participated in SFG meetings.

\section{Co-production arena 2: Policy actors and stakeholders (soil data users)}

Within the SFG, two items discussed and progressed were the soil monitoring under the Soil Monitoring Action Plan (MAP) and possible coordination with Scotland's Soil Website (SSW) (initially referred to as Scottish Soils Database and website (SSDW) project). While the Soil MAP focussed on gaps and overlaps in data, the SSW project aimed to make existing data available.

An excerpt from the Soil MAP report illustrates the perception of the members of the Soil Monitoring subgroup, which included natural scientists and policy actors from the SFG. The development of the report

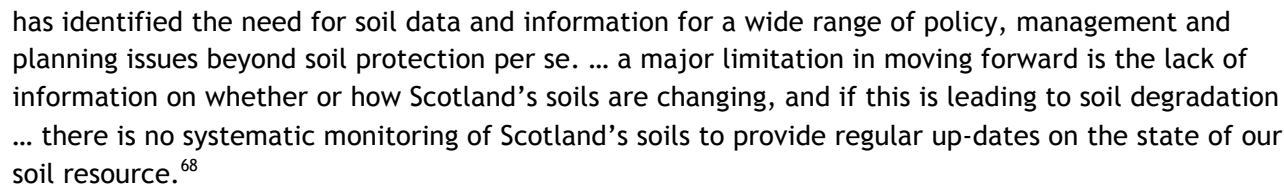

The report makes the case for a more integrated approach to soil monitoring with a view to addressing soil data needs for multiple purposes and states that 'its implementation will provide the soil data necessary for current and future stakeholder needs'. ${ }^{69}$ This quote shows how monitoring is seen to provide data which in turn is capable of addressing stakeholders' needs and protecting soils adequately.

A subgroup of the SFG (led by SEPA and SNH representatives) carried out a high level survey of organisations that comprised the SFG regarding their soil data and monitoring needs, as well as feedback on monitoring action proposed for the Soil MAP. Due to limited time and resources this was seen as a good first step. This survey fed into the Soil MAP report.

\footnotetext{
${ }^{67}$ Scottish Government, Scottish Soil Framework (SSF) Progress Report (2013a) <http:/ / www. soilsscotland.gov.uk/documents/115131209_Scottish_Soil_Framework_(SSF)_Progress_Report.pdf>

${ }^{68} \mathrm{H}$ Black, P Bruneau and K Dobbie, Soil Monitoring Action Plan (Update 3 -Implementation (Breifing for CAMERAS Monitoring Coordination Group, The Soil Focus Group, Scottish Government, 25 March 2013b) <http://www.environment.scotland.gov.uk/media/71293/soil-monitoring-action-plan-implementation-march-2013.pdf> ${ }^{69}$ Ibid.
} 
In addition, a survey questionnaire was distributed at an event introducing theSSW ${ }^{70}$ on 18 February 2013 asking for soil data needs, use of and access to soil data to identify what would be useful to present on a website. Policy makers hoped to gain additional insights from this second survey, which was initiated by soil scientists at the James Hutton Institute acting in their role as contractors for the SSW.

While the Soil MAP survey was successful in gathering responses from agencies, there was a low level of responses from 'land-based businesses' and local authorities. In particular, NFUS were consulted on behalf of farmers but did not send a response to the questionnaire, and COSLA, the representative organisation of local authorities, only responded to say they would not be able to send a response. SFG participants suggested that this could reflect a lack of awareness of the fact that soil data underpins their business practices, or reflect the diverse range of needs within a single organisation, which are not easily assessed by a single consultation at a high level. The SSW survey contacted LAs directly and received feedback from eight LAs.

Both stakeholder surveys show characteristics of a medium level of interaction. Policy actors (and natural scientists with the second survey) made an attempt to elicit stakeholder preferences for how soil data and information should best be provided, and what monitoring was required. There was a focus on consultation: actors had the opportunity to react but there was no dialogue. Those who completed the survey expressed their information needs, but this did not allow them to actively express their knowledge. Information capture was constrained by survey questions with closed answer options. The interaction was built around the Soil MAP (first survey), and a product on offer (the SSW), which was seen as valuable by those policy actors who commissioned its development (second survey); projecting, therefore, an assumption of its value onto the potential users without previously interrogating their actual needs. ${ }^{71}$ Again, there was no interaction with the land manager on the ground, and with only a quarter of local authorities.

\section{Co-production arena 3: Social scientists, core policy actors and stakeholders}

In recognition of the lack of insight into the soil data needs of land managers and local authorities, SG RESAS contacted the social scientists working in the current SG RESAS programme, expressing an interest in gauging how aware farmers and land managers are of the soils data and information that is available to underpin their decision-making, and what are their needs and attitudes towards different datasets and information sources. According to a statement in the Soil Monitoring Action Plan: 'there is a remaining gap in our understanding of the soil monitoring needs of organisations outwith (sic) Government and agency bodies e.g. local authorities, land managers, etc. A follow-up survey is required to address this gap, which could also link to the Scottish Soil Database and Website (SSDW) activities'. ${ }^{72}$ In addition, there was interest from the policy actors in how to better engage with some of the 'harder-to-reach groups'. ${ }^{73}$ During the negotiation stage (see Table 2 ), this information need from the policy actors' side was specified to include local authorities as 'harder-to-reach groups'. This term was clarified to mean that these groups had not (or only partially) responded to the previous survey consultations.

From the policymakers' viewpoint, the core questions comprised, therefore, whether: ${ }^{74}$

- So-called 'hard to reach' groups are not engaging due to the approaches taken;

- There are other reasons for not engaging;

- They perceive any needs with respect to soils data/information (and if not, why not?); and

- Groups are aware of the different soil data and info that exist.

SG RESAS welcomed the resulting interview study as an excellent example of policy needs helping to shape research. ${ }^{75}$ Policy actors recognised that in the case of local authorities these may be 'hard to reach' due to a lack of LA resources and a lack of awareness about soils data availability, rather than issues of attitude. ${ }^{76}$ Therefore, it may be surmised that the descriptions of study requirements illustrate policymaker perceptions of the issues relating to LAs' use of soil data.

\footnotetext{
70 This project comprised the development of a pilot national website for soils supported by a database holding spatial and attribute data from a range of sources. The web service was to ultimately enable easy access for interrogation and download of soil data and information.

${ }^{71}$ Although SG would have asked SEPA, SNH and other national bodies about their needs before they commissioned the website project.

72 Black, Brueneau and Dobbie (2013), above n 68, 1.

73 Personal communication by email, 26 February 2013.

${ }^{74}$ Personal communication by email, 30 May 2014.

75 Ibid.

76 Ibid.
} 


\section{Policy actor - social scientist interaction}

From the policy actors' point of view, the research needs consisted of a synthesis of existing consultation responses and some additional social research to inform, test and evaluate appropriate engagement methods. ${ }^{77}$ The social researchers argued that a semi-structured interview would be a more appropriate mechanism to elicit land managers and local authorities' soil data and information needs than a questionnaire with closed questions. Social researchers deduced that the representative bodies (NFUS and COSLA) had not responded to the questionnaire because they did not have detailed insights into how their constituencies used and accessed soil data, or for what purpose.

The social scientists drafted a question guide and policy actors commented. A policy actor - assuming a standardised questionnaire - raised the issue that the suggested line of questioning might risk an immediate negative response, which would mean the rest of the questions are not answered. The social scientists took care to point out that they planned to conduct semi-structured, in-depth interviews which allow the respondents to focus on issues of importance to them and would produce qualitative rather than quantitative data. The social scientists made clear that they found this more appropriate because of the expected diversity of views and contexts.

There was also the suggestion by the policy makers to include a question regarding how much time and resources individuals would be prepared to spend on getting new soil skills (eg, 'hands on' experience) or to get access to new soil data and information. Furthermore, they asked to include questions on the age of farmers and farm size. The social scientists explained that they understood the focus to be on understanding the way of using soil information and reasons for accessing (or not) soil data. Qualitative studies do not aim for representativeness, the sample size is small, and therefore those questions were seen as marginal by the researchers. The researchers' arguments were accepted by the policy actors.

The analysis of the level of interaction shows that major interaction with two-way communication took place between core policy actors and social scientists. Although predominantly via email, and complemented by discussion over the phone, there was an active exchange of information and knowledge. Both types of actors brought an open and communicative attitude to the process and were receptive to insights of the other party: the policy actors acknowledged the expertise in empirical social research, while the social scientists respected the insights of policy actors in the use of soil data in general and in soil policy related decision-making. Knowledge differences (eg, with regard to survey/in-depth interview methods) surfaced but were negotiated and adjusted to be mutually satisfactory.

\section{Interaction with stakeholders}

There were a number of differences in understanding held by the three actor groups. For example, the social scientists suggested a phrasing of questions around 'soil information'; the policy actors insisted that the double term 'soil data and information' (information referring to interpreted data) was essential to feature in the question guide. The responses showed that LA and land manager interviewees used the terms synonymously.

LA interviewees use soil data, in particular, for planning and contaminated land issues. Predominantly 'broad scale' information, such as land capability, is considered necessary for planning purposes, while site specific soil data, such as geological and chemical data, is necessary to determine contamination risk and migration. LA current and future soil data needs are driven by national policy. Recently, soils have featured more prominently in LA policy as a result of the increased emphasis on protecting carbon rich soils (in particular peatland, related to a recent review of the Scottish Planning Policy and the National Planning Framework), as translated from national policy targets regarding carbon emissions.

From a government point of view, LAs have access to the relevant soil data they need as they are entitled to a licence allowing them free access to a range of soil data. This current licensing system started in April 2011. It was known to some policy actors before the interview study that only a small proportion of LAs had taken up the entitlement to a licence. There had not been any systematic awareness raising with LAs. This lack of awareness led to the awkward situation that one LA interviewee commented on how they had digitised maps to help make their work easier, not recognising that these maps were already freely-available electronically, and that there were copyright issues involved. Many of the LA interviewees believed that there was a cost 
involved when accessing data, for example from the British Geological Survey, and one interviewee felt many organisations 'hold the cards close to their chest', indicating a reluctance to share soil data.

When the results of the interviews were fed back to policy actors, they acknowledged that there does seem to be a lack of internal coordination between LA departments that may require access to similar data and information. Of the ten LAs interviewed, only two held a current licence and five have never held any type of licence from the Scottish Government since $2011 .{ }^{78}$ This was not detected in the interviews because the licensing arrangements seemed unknown to the interviewees (some mentioned a 'GIS colleague' or similar who handled data access). As a result of the study, policy actors became more aware that, even if data is provided to and finds its way into LAs, knowledge of its existence cannot be assumed to be universal within the organisation, nor does widespread knowledge exist regarding how to utilise the data. Policy actors acknowledged that awareness raising for LAs is a critical requirement ${ }^{79}$ in order to enhance soil data use for LA purposes.

Several LA interviewees responded that they are unlikely to use any other soil information in addition to the information they currently use. If soil information is not directly required in order to comply with a policy or if there is no direct application for the soil data, it is unlikely that a LA will draw on soil data. There was a view from the planning perspective that they do not have to go 'to that level of detail' with regard to soil. A LA response revealed that the central issue for the location of green networks is the availability of land rather than the soil's suitability for woodland, which actually contradicts best practice advice from the Forestry Commission Scotland. A policy actor commented that this indicated the need for soil policy to be much more explicit, rather than assuming that soil issues would be adequately covered under the remit of other regulatory requirements.

Members of the farming community expressed needs for detailed and field-scale soil information to make decisions regarding nutrient application and improving soil health. Farmers obtain data on soils through a range of mechanisms mostly provided by commercial companies including: sampling and laboratory-based analysis, soil mapping using GPS positioning, and scanning of soil structure. The benefits of an online soil resource were reported, including benchmarking between farms and examples of good practice.

Given the necessary detail and likely input required for construction, the farmers questioned whether an online resource (the SSW) should be a policy priority, therefore highlighting a key divergence in perception between the policy actors and stakeholders. Farmers were uncertain that any further soil data would be provided beyond what the farming interviewees have access to at present. Policy actors agreed and commented that: 'a soil map and data can only be indicative of "reality" because of temporal changes and spatial uncertainty'. Nonetheless, were the online resource able to zoom into farm scale $(1: 15,000$ or 1:10,000 rather than 1:25,000, which is currently available), this would contribute to more accurate understandings, for example, of changes over small distances (eg, across a road, between seasons). Therefore, the policy actors concluded that there is a need to better manage expectations, for example that the functionality of an interactive online map, such as zooming in to a more detailed map scale, does not provide more detailed information if the original mapping was carried out at the coarse scale.

More information on drainage was requested, however the farmers believed that historic knowledge and practices to maintain drainage have been forgotten. Indeed, a member of the SFG commented that all records of grant-funded drainage schemes had been discarded by the Scottish Government (or its predecessor), therefore confirming the perception of 'lost' knowledge by the farmers.

Estate managers explained that they do not directly seek soil data, as this is typically the responsibility of the estate agricultural manager or tenant farmers. However, maps of Land Capability for Agriculture are consulted during the valuation, marketing and rent reviews of properties. The interviewees described their wishes for a website or online resource for soil data, in particular to access very specific information about certain small areas, and that as detailed maps as possible would be necessary (zooming in and using 1:25,000 scale). There is also a wish to find out about current conditions, and knowledge of soil data and interpretation, for example, when a farm or other property is to be sold, re-let or if exploring alternative land use systems.

The estate manager interviewees felt that their main barrier to accessing soil data and information is their lack of awareness of what is available or may be useful to them, coined as 'I don't know what I don't know'. There was agreement that if there was more publically available soil information they might make more use of

\footnotetext{
${ }^{78}$ Personal communication by email from policy actor, December 2013.

79 Ibid.
} 
it and also use it to advise others. It was suggested by both estate managers and farmers that, overall, continued efforts to raise awareness of the Scotland's Soils website and available information are necessary.

Overall, the reaction of policy actors to the responses of stakeholders confirmed that findings were similar to key points raised in their earlier survey consultation (arena 2). A policy actor expressed the recognition that, despite some feeling that activities in the past have raised awareness of soil and that policy actors have achieved their goals from the soil framework, there still remains a lot to be done.

The level of interaction with stakeholders can be described as predominantly one-way communication with a medium level of interaction. There was no direct exchange between policy actors and stakeholders but the stakeholders' responses were passed on to the policy actors in the form of a report by the social scientists. Although social scientists spoke directly with LA staff and land managers and were receptive to their insights, this was only on one occasion and information was passed on to social scientists rather than actually sharing knowledge. There was no negotiation or adjustment, and knowledge was only 'brought together' in a report which was shared with interviewees at the end of the study.

\section{Discussion}

In this paper, we have unpacked three soil governance arenas where we expected to observe knowledge coproduction. We analysed:

- Co-production arena 1: natural scientists and Soil Focus Group participants with medium to major level of interaction;

- Co-production arena 2: policy actors/natural scientists and stakeholders (soil data users, through two survey consultations) with medium level of interaction;

- Co-production arena 3: social scientists, core policy actors and stakeholders with major interaction between social scientists and policy actors, but medium to no interaction between stakeholders and policy actors.

These different levels of interaction indicate in which type of setting and between which knowledge types coproduction is most likely to occur and shape soils governance. The use of an email survey (arena 2) curtailed the opportunities for knowledge co-production because some user groups (LAs, farmers, estate managers) were not able to engage. Although the SFG already had some awareness of the differing needs of different users following the survey consultations, there were clear benefits to engaging the social scientists (arena 3 ): the results of the interview study supported what the group already sensed and provided further insights into the views and issues that exist, both in terms of user information needs and need for improved communication and awareness-raising. Although the social scientists still functioned as an intermediary (and potentially a filter), the interaction in the third arena complemented the interaction in the first two arenas in a productive way.

While some authors argue that the co-production of knowledge is more straightforward between scientists and policy makers, ${ }^{80}$ this study found that the interactions were similarly straightforward where personality and expertise of the people (eg, of the social scientist and the interviewee in the interview study; or of the social scientist and the policy actor) meant that they 'spoke the same language', which is more in line with the findings of Hickey et al. ${ }^{81}$ This may also reflect that policy actors and other stakeholders may also be trained scientists, hence individuals from different actor groups may share 'a language' and partial knowledge.

The extent to which knowledge co-production is pursued depends on the issues at stake, relevant actors and the culture of governance in the respective setting, including issues such as resources and power held by different stakeholders. ${ }^{82} \mathrm{~A}$ mix of governance styles is evident in Scottish soil governance, showing elements of network, hierarchy and market governance. There appears to be a move to increase the network governance, which requires actors to establish working relationships based on empathy and trust, and decisions made on consensus. Therefore, it seems imperative to explore different formats of knowledge co-production.

\footnotetext{
${ }^{80}$ Edelenbos et al, above n 5; S Jasanoff, States of Knowledge: The Co-production of Science and Social Order (Routledge, 2004).

${ }^{81}$ Hickey et al, above $\mathrm{n} 17$.

${ }^{82}$ Brugnach and Ingram, above $\mathrm{n} 2$.
} 
According to Brugnach and Ingram, ${ }^{83}$ three conditions foster knowledge co-production: recognising interdependencies and allowing parties to come together to build a history of reciprocal and respectful interactions; building good relationships based on trust and credibility among participants; and creating the decision space that supports collaboration. With the SFG and ongoing interactions with other partners, policy actors are creating such conditions. For example, in order to enhance soil data use for LA purposes, SNH has embarked on the publication of the SESIN series (Soil and Earth Science Information Notes) that will facilitate access to and understanding of soil information for non-soil specialists dealing with spatial planning and environmental assessment. ${ }^{84}$ However, recognising the importance of personal interaction and relationships, there is scope to explore the use of methods such as narrative, network or framing analyses that help mapping different types of knowledge while retaining their original values and forms of representation. ${ }^{85}$ Utilising a two-way approach to interaction (or 'bi-directional knowledge flows') ${ }^{86}$ would help to clarify different viewpoints; for example, policy actors had questioned specific details, seemingly contradictory statements, or how certain stakeholder comments had come about that were fed back to them from the stakeholders through the researchers. Two-way communication would allow participants to discuss and clarify these points immediately, resolving inconsistencies and misunderstandings. The 'user group' that was established under the SSW project aims to provide an opportunity for doing this via face-to-face meetings, workshops and email.

We found that knowledge co-production can enhance soil governance; in particular when it draws on multiple knowledge sources (scientific and non-scientific), and combines co-production in different arenas. This judgement is made on the basis that the involvement of different types of knowledge allows the involved actors to reconsider the problem framing and appropriate solutions, and avoid investing resources into activities that do not meet the needs of some or many types of actors. ${ }^{87}$ The interaction processes associated with knowledge co-production also help to communicate current soil policy, and recent or anticipated changes. Similar to (genuinely) participatory processes, co-production processes can help to secure buy-in and enhance the implementation of policies because they are better understood, supported and communicated to relevant stakeholders and their networks. ${ }^{88}$

Our findings also underline the importance of involving natural and social science in the co-construction process in order to increase awareness among policy actors. Each group of scientists will contribute different knowledge, the former about soils, risks, monitoring and appropriate mitigation measures, the latter about 'people's values and perceptions of soil management'. We also note that there was no interaction between social and natural scientists in arenas 1 and 2 (even though based at the same institute), which could have improved the interaction with stakeholders (eg, designing appropriate consultation and engagement methods).

In addition to the co-production process, the interaction between the different actor groups also highlighted that they framed the problem differently. The SFG members (policy actors and natural scientists) who developed the Soil MAP frame the situation in terms of a threat to soil resources that can be addressed by increased and better coordinated monitoring methods to fill perceived data gaps. The actors involved in the SSW project (policy actors and natural scientists) frame the problem as one of a lack of data or the limited access to data and information. Stakeholder groups framed the problem in yet another way, leading to very diverse soil information needs within and between user groups. Farmers view their soil as part of the farming business and require (almost real-time) information for day-to-day management decisions. Hence, any monitoring undertaken at national or even regional scale would be too coarse and outdated. A soils website (in its current state) is, therefore, perceived as of limited use to farmers. LAs perceive a limited need for additional soil data since they use soil information mainly for development planning and identifying the risk of contaminated soils. Similarly, estate managers consult soil data on the occasion of valuing property, which may not be an everyday occurrence; therefore, they perceive their soil information needs have been met. However, this group welcomed greater accessibility to soil data.

The different frames that actors apply to the problem shape how they perceive what an 'appropriate solution' is. This applied to the policy actors, who started with the perception that the stakeholders are aware of their soil data needs and could easily express these in a survey questionnaire (arena 2), even at the aggregated level

\footnotetext{
83 Ibid.

${ }^{84}$ Scottish Natural Heritage, Soil and Earth Science Information Notes (SESIN) <http://www.snh.gov.uk/planning-anddevelopment/advice-for-planners-and-developers/sois-and-development/>.

85 Burgnach and Ingram, above n 2.

${ }^{86}$ Roux et al, (2009), above n 25.

${ }^{87}$ Hegger et al, above $n$ 10; ibid.

${ }^{88}$ M S Reed, Stakeholder Participation for Environmental Management: A Literature Review (2008) 141 Biological Conservation 2417, DOI: 10.1016/j.biocon.2008.07.014.
} 
of national bodies. It also applied to the perception that making as much soil data as possible available on one central website along with interpretive information for different types of users would address the needs of a wide range of stakeholders (arena 3). This is a generalisation that became apparent when discussing drafts of this manuscript: problem framing and interpretations differ from one actor to another within the same group.

The interaction analysis along knowledge types and actor groups illustrated an explicit disconnect between administrative levels. Whilst the policy actors/bureaucrats at national and at local authority level hold a similar type of knowledge - drawing on administrative processes and contextual knowledge of policy processes - we found a disconnect between the two levels that influences soil governance. Although national policy actors stated that they have shared information about availability of soil data in the past, they were surprised at the findings of the study that showed very limited awareness of accessibility and associated costs.

\section{Limitations}

The discussion of knowledge co-production, both in the literature and among real world actors, often fails to discriminate between information and knowledge. According to Roux et al, ${ }^{89}$ information refers to organised data or interpreted data, which is explicit and can be readily transferred to another party. Knowledge, on the other hand, is defined as a mix of experiences, values, contextual information and intuition that provides a framework with which to evaluate and incorporate new experiences and information. A significant component of knowledge exists in tacit form, which is highly personal and difficult to formalise. Therefore, an analysis of knowledge co-production between groups is inherently broad-brush, glossing over the very diverse knowledge that each member of the group holds.

This diversity is exacerbated by trying to allocate actors to groups which are not clearly delimited. Faced with a literature that is full of synonyms and inconsistent use of terms, we chose to follow the distinction by Edelenbos et al. ${ }^{90}$ However, we encountered issues with summarising professional and lay knowledge under the umbrella of stakeholder knowledge, ${ }^{91}$ just as with equating professional with scientific knowledge, and lay (non-professional) knowledge with local knowledge. ${ }^{92}$ Coburn summarised both, knowledge of members of universities and governance agencies as 'professional' knowledge while Wehrens distinguished policy makers, professionals (equated with practitioners) and researchers. ${ }^{93}$

We found even the distinction of scientific and non-scientific knowledge to be controversial. In our case it became apparent that policy actors also held scientific knowledge. It is not unusual for research scientists to make a career change and join the government or a NDPB. In addition, a person may hold a scientific degree in one field, be an expert without a degree in another unrelated field, but have lay knowledge in a third field. On a similar note, researchers and policy actors also had a stake in the process; thus, they would also be stakeholders.

Although we classified actors into a number of actor groups to allow for the structured analysis of interactions between them, we acknowledge the limitations of such a classification in the face of the inherent heterogeneity of actors, person-specific tacit knowledge, and the role of beliefs and knowledge use. ${ }^{94}$ Hence, making inferences from what the individual told us about their use of soil data to the soil data use in the LA as a whole is not possible. We might have interviewed an individual who is only marginally involved in handling and interpreting soil data. Some interviewees stressed that they are responding as individuals and not representing the view of the LA. The same applies to farmers and estate managers, where even with a larger sample size, the knowledge of the individual cannot be representative for the whole actor group.

A further limitation of the study was that, for analysing the knowledge co-production processes in arenas 1 and 2 , we were limited to the written material (minutes, documents) available, and had to interpret those expost, which may have limited insights. We countered this by exchanges with people involved at the time and gathering their perceptions. In addition, the role of the natural scientists within the SFG (arena 1) from both research institutes and NDPBs, as well as in the project to develop the soils website has been underrepresented in the analysis of the arenas.

\footnotetext{
${ }^{89}$ Roux et al, above n 25.

${ }^{90}$ Edelenbos et al, above $\mathrm{n} 5$.

91 Ibid.

${ }^{92}$ Coburn, above n 12.

${ }^{93}$ Wehrens, R., 'Beyond Two Communities - From Research Utilization and Knowledge Translation to Co-Production?' (in press) Public Health.

${ }^{94}$ Edelenbos et al, above n 5.
} 
We did not analyse the issue of power, although we acknowledge its importance in both governance and coproduction processes. In general, in co-production processes that involve policy actors, the power would remain with the policy actors (possibly one specific policy actor), because they are the ones who determine when and how to engage other types of knowledge, and also the extent to which the knowledge brought into the process is then used in decision making. There is the possibility that policy actors might use the feedback from stakeholders to promote a certain agenda with regard to soil governance, for example, SSF implementation activities. For example, a policy actor recognised that the stakeholder feedback highlighted that data was still required for some degradation threats such as soil erosion and compaction, and questioned whether the policy actors could use this to reinforce the need for this sort of data. However, other actors also possess power. For example, stakeholders (including LAs) hold power in deciding to engage (or not) in any monitoring or consultation activities, or whether they utilise the SSW. With respect to scientific soils data and information, an aspect of 'power' remains with the natural scientists in that the data cannot be made accessible without their specialist input (eg, data updating, interpretation).

\section{Conclusion}

Due to the difficulties in delineating actor groups, and hence knowledge types, the use of knowledge coproduction 'as a full fledged theory - claiming law-like consistency and predictive power' 95 is not appropriate, and even misleading. Instead, the concept of knowledge co-production is beneficial 'as an idiom, 96 in helping to interpret and account for complex phenomena in an endeavour to capture the full range of factors that might play a role in determining more or less successful governance. Conceptualising knowledge co-production as a frame for developing polycentric, interactive and multi-party processes in soils governance can support network governance. Whilst reality is quite 'messy' with respect to delineating actor groups, looking at the strength and type of interaction in each arena can help show where interaction needs to be improved.

However, there is a need to further articulate how to practically manage such processes and who to involve in which context - in a policy environment where a multiplicity of decisions are made on a regular basis, in overlapping policy arenas and at different levels. In addition, there is a need to justify (transaction) costs that inevitably arise from co-production processes. Care must be taken when ascribing lack of interest or issues of attitude as a reason for non-engagement when actors may not have the resources to engage. Similarly, a lack of receptiveness to other knowledge sources may be due to actors being subject to external pressures (having to work within a specific policy framework) or an underlying mistrust or fear of the other actors. The literature on social learning and transdisciplinarity provides further insights. ${ }^{97}$

We emphasise that studies of knowledge co-production need to be explicit in how they delineate knowledge types and carefully consider nuances in actor types allocated to one group. This is supported by Wehrens, who outlines several problematic assumptions, such as the analytical a priori separation of research, policy and practice domains and the overemphasis on both the heterogeneity between domains and the homogeneity within these domains. ${ }^{98}$

Overall, policy actors became more aware of the different requirements from different users of soil data and issues involved, as well as the need for improved awareness raising and two-way communication. The interview study, providing feedback and discussing findings, along with exchanges surrounding the reflection of knowledge co-production processes in this paper, helped to stimulate debate among policy actors, which we assume will influence future soil governance. However, with the many strands of decision making and many more arenas than have been investigated in this paper, it is a challenge to link cause to effect; that is, knowledge co-production in one arena to a change in soil governance.

Ultimately, to determine whether a knowledge co-production process has been successful or not, we advocate a focus on the process and the outcome rather than the output (ie, the product). In line with Hegger et al, a successful knowledge co-production is 'a process which should be acceptable for all participating actors', meeting the criteria of salience, credibility and legitimacy. ${ }^{99}$

\footnotetext{
${ }^{95}$ Coburn, above n 12; Drawing on Jasanoff, above n 80.

${ }^{96}$ Coburn, above $\mathrm{n} 12$.

${ }^{97}$ A Carew and F Wickson, 'The TD Wheel: A Heuristic to Shape, Support and Evaluate Transdisciplinarity Research' (2010) 42 Futures 1146, DOI: 10.1016/j.futures.2010.04.025; Reed, above n 88; D J Roux et al, 'Framework for Participative Reflection on the Accomplishment of Transdisciplinary Research Programs' (2010) 13 Environmental Science and Policy 733, 10.1016/j.envsci.2010.08.002.

${ }_{98}$ Wehrens, above $\mathrm{n} 93$.

${ }^{99}$ Hegger et al, above n 10, 54.
} 